\title{
Five Forces Analysis Based on Xiaomi, a Chinese Smartphone Company
}

\author{
Wang, Jiaying ${ }^{1}$ \\ ${ }^{1}$ Xi'an Teiyi High School, Xi'an, 710054, China \\ 2857687831@qq.com

\begin{abstract}
As the development of technology and the spread of information, people's desire and needs of smartphone increases dramatically. Admittedly, smartphone plays a crucial role in human being's daily life as people use it as communication tools, game device, and portable office device. This paper analyzes one of the most famous smartphone brand in China -- Xiaomi to fully understand how it stands out in the industry. This analysis is mainly based upon Five Forces methodology to fully explain how Xiaomi operates and behaves in the smartphone industry.
\end{abstract}

Keywords: smartphone, five forces analysis, business strategy, IoT, AIoT.

\section{INTRODUCTION}

This report mainly focuses on Xiaomi, a Chinese smartphone brand and the world's third-largest smartphone marker. The below report will be analyzed using the Five Forces methodology, which is a famous business strategy tool to analyze a company's competence in its industry. Five Forces analysis includes competitive rivalry, the threat of entry, the threat of substitutes, supplier power, and buyer power.

Xiaomi's mission is to produce high-quality products at affordable prices [1]. Xiaomi's core products are smartphone series. Other businesses like its ecological chain including other products like rice cookers, electronic toothbrushes, and suitcases, etc, and its IoT, the Internet of things, connecting to Xiaomi products and collecting relevant data to make people have an affordable smart life. At the spring launch of Xiaomi in 2021, CEO Lei Jun announced that Xiaomi would enter the electric vehicle field. He had been interested in this field and invested in many projects in the past. Now it's time for Xiaomi to make its own electric vehicle products. Obviously, Lei did profound research on this industry. He knew clearly how much money it cost and he was confident with Xiaomi's ability and capital to make the idea work. Lei expressed that he would love to bet his reputation on his last start-up project. He will lead the electric vehicle team by himself to fight for MI electric cars [2].

\section{FIVE FORCES ANALYSIS}

\subsection{Competitive Rivalry}

With the popularity of the Internet, the size of the smartphone industry market has been enlarged with more brands joining the fierce competition. Customers have more options when it comes to picking the right phones for themselves. Even in China, Xiaomi has to face many other competitive rivals like Huawei, OPPO, and Vivo, etc, let alone the brands outside the country like Apple and Samsung. However, Xiaomi has its charm which is offering high-quality products at an honest price, helping it attract and retain a lot of loyal customers all around the world. However, Xiaomi also needs to face the challenges from its current competitive rivals since cost-effective strategy is easy to copy by other companies. Huawei is known by its strong R \& D capability. While OPPO, and Vivo put more energy on designing their products, which helps them earn many female customers. Outside of China, Huawei got sanction from U.S and its selling declined, giving Xiaomi a chance to enlarge its market share overseas. According to a report by Canalys, Xiaomi occupied third place in the global smartphone market during the first quarter of 2021[3], which reflects that Xiaomi's status and ability even though there are many competitive rivals in the industry.

\section{Threat of Entry}

Although there are many players in the smartphone industry, it is not easy for a newcomer to enter the 
industry or even achieve good results immediately. The smartphone industry requires the existing companies to invest lots of money on product research and development, letting alone a new company without any base to support. Newcomers need to spend much more energy and capital to catch up with the current technology that is being used by existing industry players. Except for the basic technology to enter the industry, the new companies are supposed to differentiate their products from the existing products in the market. The right strategy of product differentiation is very important for a new player. Nowadays, Apple, Samsung take most of the market share, making it a fierce competition for other smartphone brands. Apple is famous for its high-end products and product ecological chain. While Samsung is the traditional brand in the smartphone industry with a high reputation and high quality of products. Other brands like Huawei, which is prestigious with its information and communication background; and Xiaomi, which is easy to identify because it offers highquality products with the extremely affordable price; While OPPO and Vivo are designed for the young with fancy smartphone looking and other entertainment functions like music broadcast quality. All these successful brand settings are the barriers to the new entries. Therefore, it's relatively difficult for a company to enter the market and gain a great market share shortly.

\subsection{Threat of Substitutes}

Xiaomi is facing a high threat of substitutes in the industry. As we all know, Xiaomi's strategy is offering relatively high-quality products at an extremely honest price, helping Xiaomi take over a large market share at the beginning. However, with the brands like OPPO and Vivo, and Huawei getting popular with similar pricing positions, Xiaomi seems to have less advantage in front of price competition. Except for form the price, Xiaomi also faces technology challenges from its substitutes. Apple is famous for its own-designed system IOS, and the relevant products based on the systems like IPad, Apple Watch, etc, to fit its laptop system macOS. Moreover, its classic product design and high-end quality also make it an easy-identified brand. Samsung is the pioneer brand in the smartphone industry for a long time with loyal customers who are convinced by its highquality products with rapid updating technology. As to Huawei, the company also invests tons of capital on its own-designed chips and has a strong background related to information and communication. Above substitutes brands all have their core technology, making Xiaomi in a disadvantaged place when it comes to tech through comparison. However, Xiaomi has its charm with its IoT, connecting products to the Xiaomi platform to attract more customers.

\subsection{Supplier Power}

Since Xiaomi doesn't have its own-designed system nor widely use its own-designed chips, Xiaomi has a relatively weak supplier power. Especially during the pandemic, many smartphone companies faced a shortage of chips [4]. Therefore, the chip market becomes a seller's market. Chip manufactures who made limited chips are being watched closely by smartphone buyers. Other component suppliers not only offer components to Xiaomi but also other companies. They are driven by money. Xiaomi advocates using the least of money to buy relatively high-quality products, indicating that its component suppliers won't earn much profit on a single product. Xiaomi's advantage is the large shipment, so component suppliers could still earn more money from Xiaomi by producing more products. Due to the obstacles given by suppliers outside of China in early time, and the growth of domestic suppliers, Xiaomi switched its strategy to work more with Chinese suppliers. Inside of China, many component suppliers wanted to cooperate with Xiaomi because it could increase their reputation and quickly rank the top if they take the big orders from Xiaomi. In addition, Xiaomi is a tech giant company in China with a good reputation and healthy cash flow. It is worthy for component suppliers to work with Xiaomi and get the money back quickly, which is important for manufactures. Therefore, in China, Xiaomi has relatively strong bargaining power with its suppliers.

\subsection{Buyer Power}

Xiaomi has accumulated a lot of loyal customers. The contributor to this is Xiaomi's product strategy that only sells good quality products at an affordable price, which helped Xiaomi got the very first customers in the market even now. Young people are the main buyer power because they recognize the concept of Xiaomi products. Now with the good economic environment, and more available money that can be used by people, Xiaomi's price advantage isn't that obvious, especially with the competition of Huawei, OPPO, and Vivo, which promote the fancy-looking product with similar price. The rivals' competition put Xiaomi under pressure. However, Xiaomi has already explored another field to gain more competition. That is Xiaomi's IoT ecosystem, which connecting other products like floor sweeping robots, smart home door lock, and Internet washing and drying machine, etc, to Xiaomi's platform to create a smart life for customers at an affordable price[5]. Peripheral products that Xiaomi have are electric toothbrush, millet bracelet, electric rice cooker and so on. Compared to Apple which has limited product lines, Xiaomi's product lines can be called abundant, attracting many customers to want to enjoy smart life at an affordable price. Entering the electric vehicle field also increases the product variety. All these products are like 
platforms that collect customers' data and information, helping Xiaomi understand customer usage preferences more. Based on this, Xiaomi could design more desirable products to keep customers' loyalty and gain more customers.

\subsection{Corresponding Strategy}

The corresponding strategy for Xiaomi is to explore new business to make best use of the advantages and bypass the disadvantages. The main reason that Xiaomi made its mind to enter the electric vehicle industry is that the good time for smartphones is gone gradually. The room for innovation is limited. In recent years, customers could see more improvements on something like the screen quality, battery life, and camera quality of a smartphone. However, no matter how creative the new products are, they all have similar functions and the final form is between smartphones and tablets. As we look at the trend of the global sales of all smartphones in recent years, we could find that the trend is almost flat, indicating the bottleneck of the smartphone industry. While almost the same time, the electric vehicle industry is getting popular and grabs customers' attention. It is a good chance for tech giants to tell a new story to keep investors' confidence and embrace the new future. The electric vehicle industry is such a story for investors to have a broad imagination space. Xiaomi has its loyal customer foundation, technology base, and enough capital to throw itself to explore the new industry.

Xiaomi still needs to be aware of its disadvantages and try to overcome them. These disadvantages are mainly listed below. The current situation of the electric vehicle industry is also very competitive. Xiaomi has to face multiple challenges from traditional manufacturers and new car manufacturing forces. Since Xiaomi entered the electric vehicle industry late, it doesn't have technology accumulation. Moreover, the cycle of building a car is long, which is totally different from the logic of building a mobile phone. It has many uncertain factors and high risks. The huge investment required in car building will distract Xiaomi, affecting the cash flow and dragging down the existing main business. If Xiaomi fails, it definitely seriously affects Xiaomi's reputation.

However, Xiaomi also has advantages. First of all, the Chinese government actively promotes the development of new energy, and the electric vehicle industry has a broad market prospect. Second, Xiaomi has sufficient funds and contacts in the society from government to private companies. Xiaomi could learn from the experience and lessons of pioneers in the industry to avoid unnecessary failures. Lei Jun has invested in dozens of automobile companies in the industry, all of which are available resources. The mobile phone industry chain and automobile industry chain have something in common. If Xiaomi can win the battle in the electric vehicle industry, MI cars will be the next platform to connect other Xiaomi products without paying the platform fees, at which time, Xiaomi would realize the final AIoT with cars involved. So far, the voice to support Xiaomi is very loud because young people are expecting MI cars to continue the cost-effective strategy. Therefore, more people could afford to have their own electric cars.

\section{BUSINESS MODEL AND STRATEGIES OF XIAOMI}

Xiaomi smartphones are only sold through the ecommerce platform, eliminating the intermediate fees to the greatest extent. Through the direct selling on internet, operation cost can be greatly reduced, thus degrading the sales price of the terminal. Meanwhile, Xiaomi has never advertised. Keeping the transparency of costs and good reputation of the products is the secret of Xiaomi's success.

Xiaomi also chooses to press the price to the lowest, and keep the configuration of the products to the highest. As an Internet company, Xiaomi is more concerned about the reputation of users. As long as there are enough users, profit is not a problem. For example, Xiaomi may only sell 1 million smartphones a year, but it attracts tens of millions of mobile Internet users. Google's free Android is to make money from searching and advertising. Amazon's low-cost loss selling of its Kindle is the same idea. As long as there are enough users, they can make a lot of money by selling content and services through terminals. Xiaomi builds its own smartphone brand, and has its own system level product services, so that users are not only their own smartphone users, but also their own system users. From this point of view, Xiaomi and Apple are very similar. The difference is that Apple's profits mainly come from hardware, while Xiaomi does not rely on hardware to make money.

However, there are limitations in Xiaomi's business strategies based upon Five Forces analysis mentioned above. The most serious ones are supplier power and buyer power.

\section{CONCLUSION}

This report mainly uses the Five Forces model to analyze Xiaomi's competence in the smartphone industry. Even though Xiaomi's business strategy that offering high cost-effective products gained big success before, Xiaomi still needs to pay attention to differentiate its products from its current rivals as to the smartphone industry. Customers could buy similar products of other brands with similar budget because the switch cost of customers is low. Hence, the most urgent thing for Xiaomi is to create its own-designed chips to have core technology, rather than being subject to other suppliers. In addition, the IoT ecosystem is another highlight of Xiaomi, thus Xiaomi needs to enhance this strategy to explore more smart products for its customers. Entering 
the electric vehicles field is such a good chance to continue this strategy. In the near future, maybe we could see the MI cars replacing MI smartphones to be the new platform which helps Xiaomi realize its ultimate AIoT.

\section{REFERENCES}

[1] Tse, E. (2021). Tech in Asia - Connecting Asia's startup ecosystem. Retrieved 31 May 2021, from https://www.techinasia.com/talk/happened-xiaomi

[2] Kharpal, A. (2021). Chinese smartphone giant Xiaomi to launch electric car business with $\$ 10$ billion investment. Retrieved 30 May 2021, from https://www.cnbc.com/2021/03/30/chinas-xiaomito-launch-electric-car-business-and-invest-10billion.html

[3] Canalys, 2021. Global smartphone market Q1 2021. Retrieved $30 \quad$ May 2021, from https://www.canalys.com/newsroom/canalysworldwide-smartphone-market-Q1-2021

[4] Shein, E. (2021). The global chip shortage: What caused it, how long will it last?. Retrieved 30 May 2021, from https://www.techrepublic.com/article/the-globalchip-shortage-what-caused-it-how-long-will-it-last/

[5] Yang, H., Ma, J., \& Chattopadhyay, A. (2021). How Xiaomi Became an Internet-of-Things Powerhouse. Retrieved $30 \quad$ May 2021, from https://hbr.org/2021/04/how-xiaomi-became-aninternet-of-things-powerhouse 